\title{
El Ciprés en la Mitología Mexicana.
}

\author{
Por el Dr. B. P. REKO.
}

Todo el mundo sabe que el ciprés es un árbol fúnebre que se planta sobrte tumbas, un rito que proviene del oriente; pero poco conocido es el hecho que también en el México antiguo era árbol de los cementerios, como lo indica su antiguo nombre en nahuatl "teotlale" (quahuitl) que quiere decir "árbol del campo santo" (teotlalli, tierra de dios; quahuitl, árbol). En un himno que nos conservó Sahagún, el ciprés es identificado con la temible diosa de la muerte Cihua-coatl ("la mujer-culebra") la que, según mis investigaciones, ha de ser identificada con la Vía Láctea que, efectivamente, abraza todo nuestro mundo a semejanza de una serpiente gigante - como el Irmingandr de la mitología nóndica-, y que entre los incas simbolizaba la "tierra celeste" y en México el "camino de los muertos" ó de las almas de los guerreros muertos, que flotaban como vilanos en un torbellino. Pero la Cihua-coatl representa no sólamente la muerte, sino también la vida nueva, por cuyo motivo se llama Tonan-tzin ("nuestra madre") la que dió parto a los dioses (Teteo-i-nan, madre de los dioses) y a los mortales a los que formó en el infierno de los huesos pulverizados. Es notable que los chinos tienen un mito idéntico respecto de su diosa de la tierra $N u ̈$ Kua Shi ("la que tiene cuerpo de culebra y cabeza bovina"), la que ha formado la humanidad de la tierra amarilla.

Puesto que el ciprés es un árbol siempre verde, simboliza la vida v su reqeneración. como se ve en su nombre en zapoteco "yagaguichi" ("árbol de la vida") y en alemán ("Lebensbaum"). Yagaguichi-ciña ("árbol de la vida eterna") es el nombre zapoteco del ahuehuete (Taxodium mucronatum). Hay que notar que existe una cierta confusión en la nomenclatura vulgar de estos coniferos, notable también en la mitología. Los nombres de ciprés, cedro y sahino son aplicados indistintamente a Cupressus, Juniperus y $\mathrm{Ta}$ xodium. En la isla de Chipre fué adorado una diosa de la tierra que se 1lamaba Beroth, palabra fenicia que siqnifica ciprés. Es afín a la Cibeles de los helenos cuyo árbol sagrado era un pino. Cipariso de Creta fué transformado por Apolo en un ciprés a causa del dolor que experimentó nor la muerte de su venado favorito. En Boloña, el Juniperus sabina es llamado "árbol de los hrujos", porque prodice aborto, a semeianza del tajo alemán. En China el cedro simboliza el amor fiel de una pareja, matada por un rey celoso

Reko BP. 1948. El ciprés en la mitología mexicana. Boletín de la Sociedad Botánica de México 6: 29-31. 
quien la mandó enterrar separadamente, pero sobre sus tumbas crecieron dos cedros que unian sus copas. De modo semejante, nos cuenta un mito de los mixtecas que su raza fué creada por dos altos sabinos cerca de una fuente, cuyas hojas se mezclaban en la fuente $y$ al tocar tierra fueron transformados en guerreros y doncellas. Puesto que en la mitologia la Via Láctea era cementerio y sementera al mismo tiempo, es manifiesto que nuestros antepasados tenian un concepto bastante claro de nuestra moderna teoría de las galáxias en cuyos torbellinos nebulosos se forman y se deshacen los mundos.

Sahagún nos ha legado un antiguo loor a la Cihuacoatl, suprema diosa del panteón mexicano, cuyas primeras estrolas en nahuatl:

"Quavi, quavi, quilaztla coaeztica xayavaloc

viviya quavivitl vitzalochpan chalima avevetl yecolhua" son traducidas a mi modo de la siguiente forma:

"Arbol de los árboles, ciprés siempre verde,

(como) culebra roja eres pintado,

(comc) peluza de águila es tu copa,

ahuehuete del reino de los muertos en Colhuacan".

Comentario: Quilaztii, un sobrenombre de la Cihuacoatl, es derivado de quil-tic, verde; tlaz-can, ciprés. Su tronco rojo se tuerce como una culebra. Chal-man (de challi, hueso; man, dominio) es nombre de la Via Láctea, reino de los muertos. Ahuehuetl (atl, agua; huehuetl, el muy grande, gigante) es otro simbolo de la Via Láctea, como támbién lo is Col-nua-can (colli, gancho, cosa curvada; ,hua, grande; can, lugar).

De los otros apelativos de esta diosa menciono los siguientes: To-nan yauh-cihua-tzin ("nuestra madre, la mujer valiente") es el nombre de la diosa como parturienta. El árbol "nanche" (nan-tzin) recibe su nombre de ésta diosa del parto, porque su raiz es usado para producir aborto.

Cuauh-cihuatl ("mujer-águila"). Es un nombre de la partera, pues en el calendario zapoteco el signo de cuauhtli ("águila"), que pertenece al signo de Virgo, es substituido por "ñaa", palabra que significa madre o partera. En el calendario maya corresponde a "men". Ah men es el hombre sabio, pero como en el signo de Virgo se trata siempre de una mujer, ha de ser ix men (la mujer sabia), que al igual de la "sage femme" de los franceses, significa la partera.

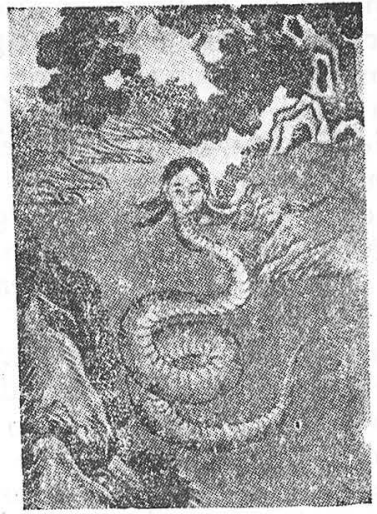

Nu Kua Shi 
Mazatl colivaca ("cierva de Colhuacan") Col-hua-can significa "lugar de la curva gigante" (colli, gancho, cosa curvada; hua; grande; can, lugar) con referencia a la vía láctea. Un nombre análogo de la Edda es Bestla ("la vaca", de beest, bestia; la, sufijo femenino), hija del gigante Bolthorn ("la curva temeraria", de bold, audaz; thorn, espina, cosa curvada). A semejanza de Isis, la diosa de la fertilidad, representada con cuernas de vaca, la diosa china Nü Kua Shi tiene también cabeza de vaca, y la Cihuacoatl tiene en su lugar dos cabezas de venado (Qua-xolotl, cabezas gemelas) con referencia a la bifurcación de la Via Láctea. Igualmente. los indios iroqueses conocen una serpiente gigante con cuernos de bisonte. Al nombre azteco Chantico ("la escondida", porque la Via Láctea es solamente visible en noches oscuras, corresponde él de la diosa teutona "Hulda. ("la escondido"), cuya espalda hueca está rellena con zacate ("malinalli", otro nombre de la Coacihuatl). Quaxolotl Chantico es idéntico con "X balan ceh" ("la cierva escondida") del Popol Vuh. En China, la galaxia es comparada con una vaca coja, (con relación al movimiento lento de este astro), semejante a la vaca nórdica Audumbla ("la vieja tropezadora", de auld, viejo; tumble, tropezar; la, sufijo femenino).

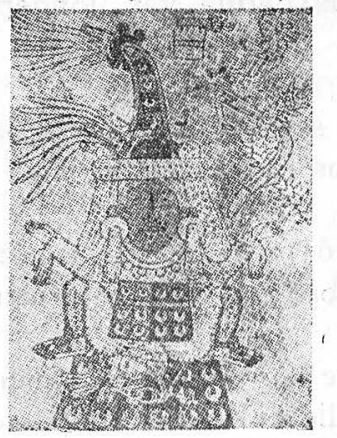

Tonantzin

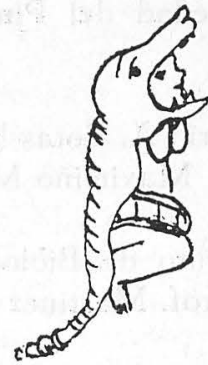

Quilaztli ó Cihuacoatl. 